\title{
Temperature oscillation coupled with fungal community shifts can modulate warming effects on litter decomposition
}

\author{
Christian K. Dang, ${ }^{1,2,3,5}$ Markus Schindler, ${ }^{1,4}$ Eric Chauvet, ${ }^{2,3}$ and Mark O. Gessner ${ }^{1,4}$ \\ ${ }^{1}$ Department of Aquatic Ecology, Eawag, Swiss Federal Institute of Aquatic Science and Technology, 6047 Kastanienbaum, Switzerland \\ ${ }^{2}$ Université de Toulouse, UPS, INP, Laboratoire d'Écologie Fonctionnelle (EcoLab), \\ 29 Rue Jeanne Marvig, 31055 Toulouse Cedex, France \\ ${ }^{3}$ CNRS, EcoLab, F 31055 Toulouse, France \\ ${ }^{4}$ Institute of Integrative Biology (IBZ), ETH Zurich, 8092 Zurich, Switzerland
}

\begin{abstract}
Diel temperature oscillations are a nearly ubiquitous phenomenon, with amplitudes predicted to change along with mean temperatures under global warming scenarios. Impact assessments of global warming have largely disregarded diel temperature oscillations, even though key processes in ecosystems, such as decomposition, may be affected. We tested the effect of a $5^{\circ} \mathrm{C}$ temperature increase with and without diel oscillations on litter decomposition by fungal communities in stream microcosms. Five temperature regimes with identical thermal sums (degree days) were applied: constant $3^{\circ}$ and $8^{\circ} \mathrm{C}$; diel temperature oscillations of $5^{\circ} \mathrm{C}$ around each mean; and oscillations of $9^{\circ} \mathrm{C}$ around $8^{\circ} \mathrm{C}$. Temperature oscillations around $8^{\circ} \mathrm{C}$ (warming scenario), but not $3^{\circ} \mathrm{C}$ (ambient scenario), accelerated decomposition by $18 \%\left(5^{\circ} \mathrm{C}\right.$ oscillations) and $31 \%\left(9^{\circ} \mathrm{C}\right.$ oscillations), respectively, compared to the constant temperature regime at $8^{\circ} \mathrm{C}$. Community structure was not affected by oscillating temperatures, although the rise in mean temperature from $3^{\circ}$ to $8^{\circ} \mathrm{C}$ consistently shifted the relative abundance of species. A simple model using temperature growth responses of the dominant fungal decomposers accurately described the experimentally observed pattern, indicating that the effect of temperature oscillations on decomposition in our warming scenario was caused by strong curvilinear responses of species to warming at low temperature, particularly of the species becoming most abundant at $8^{\circ} \mathrm{C}$ (Tetracladium marchalianum). These findings underscore the need to consider species specific temperature characteristics in concert with changes in communities when assessing consequences of global warming on ecosystem processes.
\end{abstract}

Key words: Alatospora acuminata; aquatic hyphomycetes; biodiversity; climate change; ecosystem functioning; fungal diversity; Heliscus lugdunensis; litter decomposition; microbial community structure; stream microcosms; Tetracladium marchalianum.

\section{INTRODUCTION}

The recent Intergovernmental Panel on Climate Change report (IPCC 2007) predicts large temperature increases $\left(1.1^{\circ} 6.4^{\circ} \mathrm{C}\right)$ during the current century. Such scenarios have prompted concerns about ecosystem consequences of global warming and have rekindled interest in ecological effects of temperature (Walther et al. 2002, Parmesan 2006). Warming speeds chemical reactions and enhances biological activities (Davidson and Janssens 2006, Davidson et al. 2006). As a result, it can have profound direct and indirect repercussions on ecosystem processes such as primary production and decomposition (Hobbie 1996, Knorr et al. 2005, Cornelissen et al. 2007), arguably the two most fun damental ecosystem processes in the biosphere. Fur

Manuscript received 3 December 2007; revised 19 May 2009; accepted 21 May 2008. Corresponding Editor: D. A. Wardle.

${ }^{5}$ Present address: Department of Zoology, Ecology and Plant Sciences, University College Cork, Cork, Ireland. E mail: C.Dang@ucc.ie thermore, because the balance of these processes is instrumental in determining $\mathrm{CO}_{2}$ concentrations in the atmosphere, any relative change in global rates of primary production and decomposition will have important feedbacks on climate (Davidson and Janssens 2006).

The rise in mean temperatures anticipated by climate models dominates the current debate on global warm ing. Mean values, however, are not the only aspect of temperature regimes that can have large repercussions on ecosystems. Another crucial component is tempera ture variation (Robeson 2002). It occurs at various time scales and includes regular fluctuations between day and night. Such diel temperature oscillations, driven by alternate daytime warming and nighttime cooling (Pradhan 1945, Pattee 1975, Vannote and Sweeney 1980, Sweeney 1984, Easterling et al. 1997), have essentially been ignored in attempts to forecast impacts of global warming on ecosystems (Easterling et al. 1997, Walther et al. 2002, Fierer et al. 2005, Davidson and Janssens 2006). This contrasts with climate scenarios that predict warming to be generally more pronounced 
during the night and less during the day, resulting in diminishing temperature amplitudes between daytime and nighttime (IPCC 2007). The consequences of altered diel amplitudes for evaluating effects of climate change on ecosystem processes may be considerable given that temperature oscillations can have large effects, both direct and indirect, on the activity of organisms (Pradhan 1945, Sweeney 1984, Kuehn et al. 2004).

Attempts to predict responses of ecosystem processes to temperature have generally assumed either linear (degree day relationships) or exponential (Van't Hoff or Arrhenius models) increases in activity as temperature rises (Fierer et al. 2005, Hyvönen et al. 2005, Weston and Joye 2005, Davidson and Janssens 2006, Davidson et al. 2006). However, species typically show more complex response patterns characterized by a rapid increase in activity at low temperature, an inflection point, and an optimum beyond which activity sharply drops (Blanchard et al. 1997, Pietikainen et al. 2005, van der Heide et al. 2006). This pattern suggests that effects of rising temperature on ecosystem processes may be more intricate than is commonly assumed. Characteris tic response patterns of species to altered temperature regimes thus may add to, and interact with, the warming induced changes in community structure that is predicted for the future (Walther et al. 2002). In addition, temperature sensitivity tends to be particularly pronounced at low temperatures (Davidson and Jansson 2006), as evidenced for litter decomposition in cold biomes where $\mathrm{Q}_{10}$ values commonly vary between 3 and 4 as opposed to the usually observed range of 23 (Aerts 2006).

The aim of this study was to assess consequences of diel temperature oscillations on decomposer community structure and litter decomposition. We addressed this issue by conducting experiments in stream microcosms with known fungal communities at two mean daily temperatures that reflected the current situation in temperate streams and a global warming scenario. Temperature in microcosms was either held constant or allowed to oscillate around the mean. To gain a mechanistic understanding of the observed effect on decomposition (see also Moorhead and Sinsabaugh 2006), we also determined growth responses of the dominant species to temperature and used these data in a simple decomposition model, to assess whether relative rates of decomposition expected by a given community under constant and oscillating temperature conditions could account for the empirically observed patterns.

\section{Material And Methods}

Thirty microcosms mimicking natural stream condi tions (see Suberkropp [1991] for details) were supplied with alder leaf discs $(95132 \mathrm{mg}$ ) and inoculated with fungal spores (Dang et al. 2005). Microcosms consisted of $50 \mathrm{~mL}$ glass chambers aerated from the bottom by a continuous flow of filtered air that kept leaf discs in

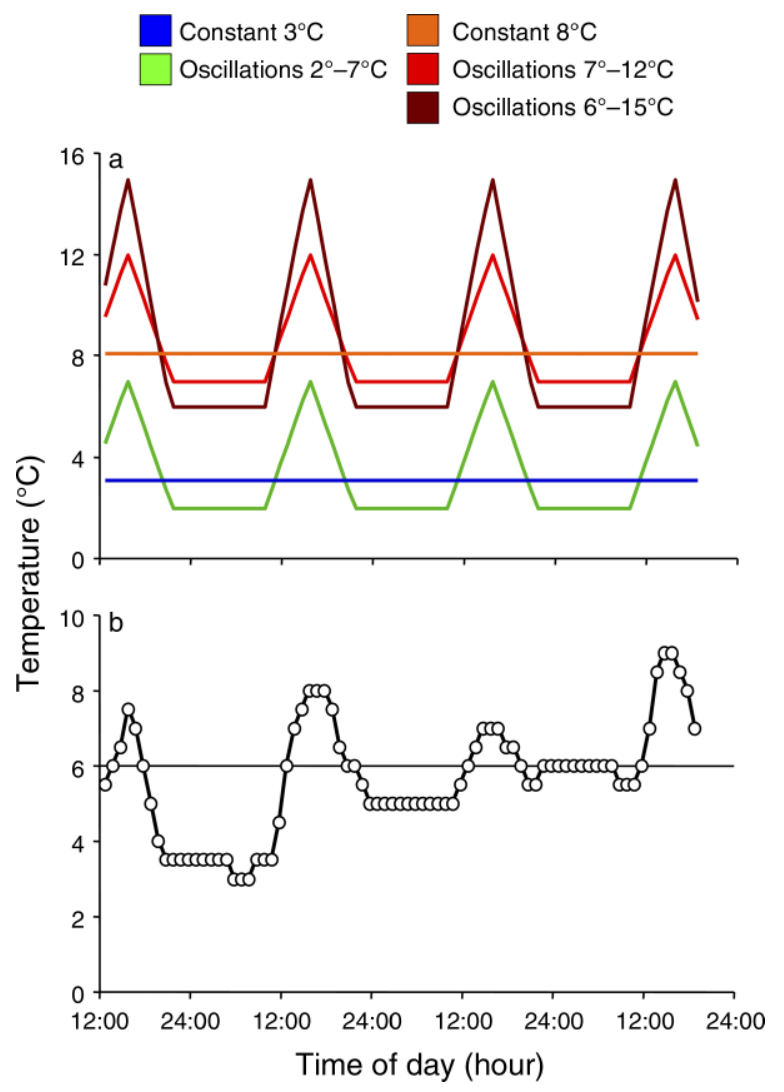

FIG. 1. (a) Five temperature regimes used in the microcosm experiment to test for effects of mean temperature and diel temperature oscillations on litter decomposition rate. (b) An example of diel temperature oscillations recorded in winter (January 2005) in a natural stream located in France.

motion. A tap at the bottom allowed aseptic drainage of the microcosms and fresh medium could be added at the top. A mix of nine aquatic hyphomycete species was used to establish realistic fungal communities (see Plate 1). These included Alatospora acuminata Ingold (CERR28 1464) [CERR stands for Centre d'Écologie des Ressources Renouvelables], Flagellospora curvula Ingold (CERR28 1456), Goniopila monticola (Dyko) Marvanová and Descals (CERR28 1455), Heliscus lugdunensis Saccardo and Thérry (CERR28 1453), Lemonniera aquatica de Wildeman (CERR28 1459), Tetracladium marchalianum de Wildeman (CERR28 1454), Tricladium chaetocladium Ingold (CERR83 225), Tumularia aquatica (Ingold) Descals and Marvanová (CERR28 1461), and Anguillospora longissima (Saccar do and Sidow) Ingold (CERR28 230). A total of 4500 spores (500 spores of each species) was used as inoculum. Liquid medium at pH 7.0 (per liter: $100 \mathrm{mg}$ $\mathrm{CaCl}_{2} \times 2 \mathrm{H}_{2} \mathrm{O}$ [number of molecules of $\mathrm{H}_{2} \mathrm{O}$ ], $10 \mathrm{mg}$ $\mathrm{MgSO}_{4} \times 7 \mathrm{H}_{2} \mathrm{O}, 10 \mathrm{mg} \mathrm{KNO}_{3}, 0.55 \mathrm{mg} \mathrm{K}_{2} \mathrm{HPO}_{4}$, and $0.5 \mathrm{~g}$ morpholino propane sulfonic acid [MOPS]), was replaced every third day using sterile technique (Dang et al. 2005). 
The experimental design involved a series of treatment combinations in which the mean daily temperature and the magnitude of diel temperature oscillations were manipulated independently (Fig. 1a). Specifically, six microcosms each were kept at a constant temperature of $3^{\circ}$ or $8^{\circ} \mathrm{C}$, where $3^{\circ} \mathrm{C}$ is a common fall and winter temperature in temperate streams, and $8^{\circ} \mathrm{C}$ represents a global warming scenario. Six additional microcosms each were subject to $5^{\circ} \mathrm{C}$ oscillations around $3^{\circ}$ and $8^{\circ} \mathrm{C}$, resulting in diel ranges of $2^{\circ} 7^{\circ}$ and $7^{\circ} 12^{\circ} \mathrm{C}$, respective ly. An additional set of microcosms was exposed to greater diel oscillations $\left(6^{\circ} 15^{\circ} \mathrm{C}\right)$ with a mean of $8^{\circ} \mathrm{C}$. Oscillations were asymmetric around daily means to mimic patterns observed in natural streams (Fig. 1). Sterile controls were kept at $3^{\circ}$ and $8^{\circ} \mathrm{C}$. Temperature regimes were accomplished by placing microcosms in programmable temperature controlled incubators.

The duration of incubations was varied among treatments in such a way that decomposition in all microcosms proceeded to about the same stage. This was achieved by adjusting length of incubations to the expected mass loss at different temperatures using the linear degree day model. Although temperature normal ization based on an exponential response to temperature increases (i.e., Van't Hoff or Arrhenius model) would likely have been more realistic, the degree day approach was chosen as a first approximation that has been widely used, not least in litter decomposition studies in streams (e.g., Irons et al. 1994, Gessner et al. 1998). To raise chances of detecting effects among treatments, we stopped the incubations at a time when visual inspection indicated that about half of the initial leaf mass was lost in the three $8^{\circ} \mathrm{C}$ treatments. Thus, microcosms were harvested after 62 days at $8^{\circ} \mathrm{C}$ and after 162 days at $3^{\circ} \mathrm{C}$, corresponding to 496 and 486 degree days, respectively. At this point all remaining leaf material in microcosms was collected, dried, and weighed to the nearest $0.1 \mathrm{mg}$. Total spore production of each fungal species was also determined to characterize fungal community structure (Gessner et al. 2003). To this end, spore suspensions collected from a given microcosm every time the medium was replaced were pooled and aliquots filtered through $5 \mu \mathrm{m}$ membrane filters before staining, identi fying and counting the spores trapped on the filter at 200× magnification (Dang et al. 2005).

In addition to the microcosm experiment, growth rates of the three fungi dominating the microcosm communities were determined at 17 temperatures ranging from $2^{\circ}$ to $24^{\circ} \mathrm{C}$. Agar plugs from the leading edge of growing colonies were placed on $1 \%$ malt extract agar (2\% agar, $20.0 \mathrm{~mL}$ total volume, $90 \mathrm{~mm}$ diameter Petri dishes) and colony extension (mean of four radial measurements) was measured after 15 days (Chauvet and Suberkropp 1998). Growth was assumed to reflect general metabolic activity. Cardinal points and shape of the temperature growth curves were determined by nonlinear regression analysis. The following model was used (Blanchard et al. 1997):

$$
\begin{aligned}
& \mu(T)=\mu_{\mathrm{opt}} \times\left(\begin{array}{cc}
T_{\max } & T \\
\hline T_{\max } & T_{\mathrm{opt}}
\end{array}\right)^{\beta} \\
& \times \exp \left[\beta \times\left(\begin{array}{ccc}
T_{\max } & T & 1 \\
\hline T_{\max } & T_{\mathrm{opt}} & 1
\end{array}\right)\right]
\end{aligned}
$$

where $\mu(T)$ is the fungal growth rate at temperature $T$ $\left({ }^{\circ} \mathrm{C}\right), \mu_{\mathrm{opt}}$ is the growth rate achieved at the optimal temperature $T_{\text {opt }}, T_{\max }$ is the temperature where growth ceases (i.e., where the curve subtends the $x$ axis), and $\beta$ is a dimensionless scaling factor. The curves described by this equation have a sigmoid shape until $T_{\text {opt }}$ is reached and then drop to 0 . Parameters of temperature response curves were estimated by nonlinear regression analysis using the least square Simplex procedure in MATLAB version 6.5 (MathWorks 2002). Confidence limits $(95 \%)$ of each regression were estimated by first generating a population of 200 curves by bootstrap (Blanchard et al. 1997). Each of these was obtained by adding randomly drawn normalized residuals to the values estimated by the regression at each of the 17 temperatures used in the growth experiments and subsequently calculating a new regression through the generated data points. The 2.5 and 97.5 percentiles, respectively, for each temperature point (increments of $0.1^{\circ} \mathrm{C}$ between $1.6^{\circ}$ to $24^{\circ} \mathrm{C}$ ) were then connected to generate the lower and upper bounds defining $95 \%$ confidence limits of regression curves.

The decomposition of litter by fungal communities at $3^{\circ}$ and $8^{\circ} \mathrm{C}$ was simulated with a model that describes fungal activity and litter mass loss as a function of species, temperature and time (Table 1). To some extent, this model was similar to the decomposition model by Moorhead and Sinsabaugh (2006) except that the latter was oriented towards the interactions between leaf chemical composition, litter decay, and microbial dynamics, and does not include a temperature compo nent. The purpose of our model was to ascertain whether dominance shifts in fungal communities could account for the empirically observed response patterns of decomposition to oscillating vs. constant tempera tures, but we caution to use this model for predictive purposes. Assumptions were that degradative activity of fungi is directly proportional to (1) fungal biomass and (2) labile litter mass (Moorhead and Sinsabaugh 2006), the rationale for the latter being that quality of the labile litter fraction changes continuously with the most easily degradable components being utilized first. Further assumptions were (3) that degradation is inversely proportional to the average fungal growth efficiency (E) (Hieber and Gessner 2002), and (4) that spore production is proportional to the relative importance of fungal hyphae in leaves (Table 1). Use of average growth efficiency is a simplification because growth efficiencies tend to vary (e.g., Schimel and Weintraub 2003, Buesing and Gessner 2006). However, the average value we used was from a microcosm study by Suberkropp (1991) who reported growth efficiencies integrated over the entire 
TABLE 1. Equations of a model describing temperature effects on fungal litter decomposition.

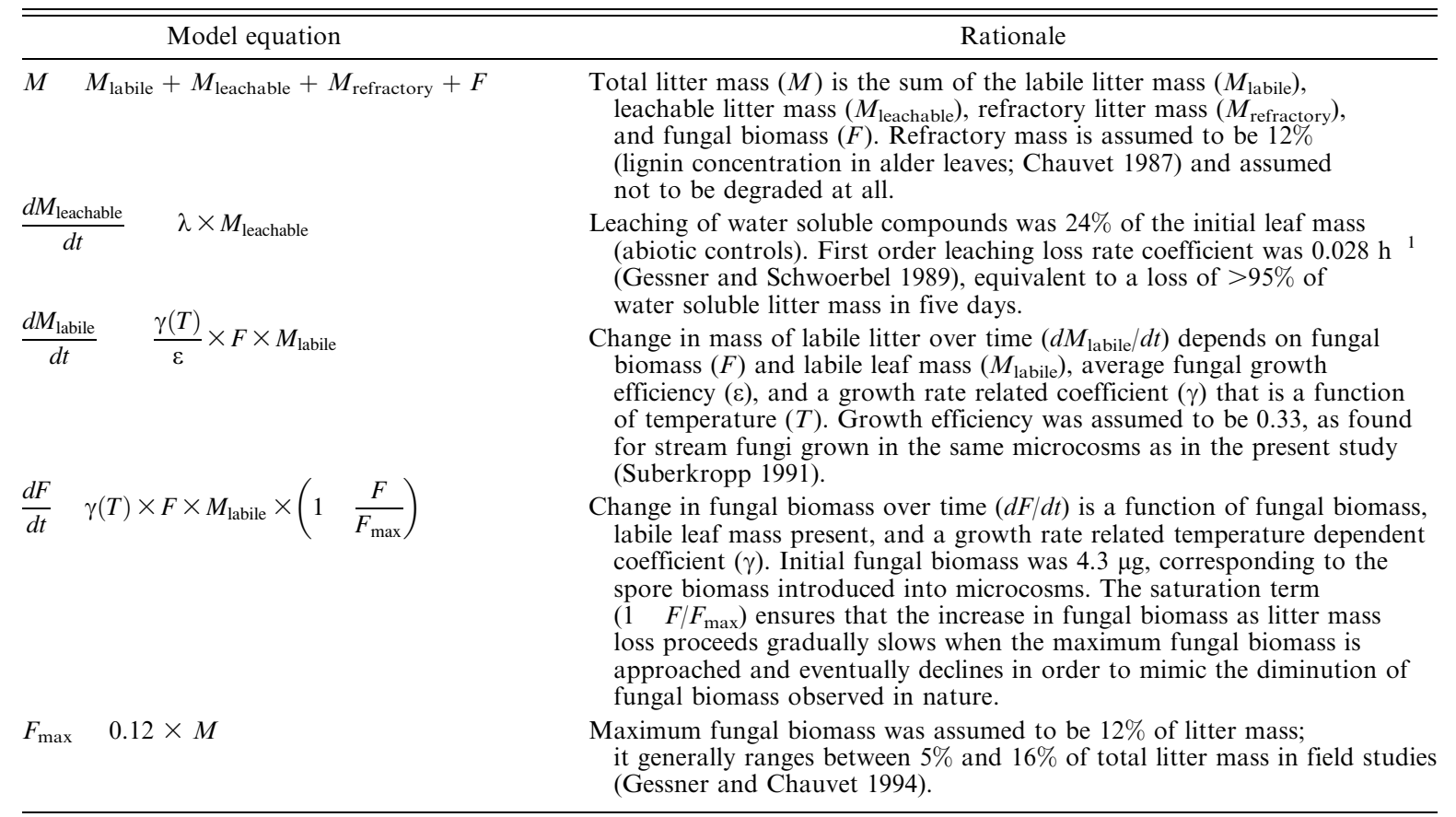

decomposition process, just like the situation in the present study. Degradative activity on leaves was estimated by scaling the litter mass loss predicted by the model (starting at $100 \mathrm{mg}$ ) to the observed litter mass loss at constant temperatures of $3^{\circ}$ or $8^{\circ} \mathrm{C}$, based on the temperature growth relationship of the dominant species and the species' relative proportions in commu nities. This scaling step limits the extrapolation strength of the model but it was necessary because (1) growth was measured on agar medium rather than on alder leaves and fungal species have different growth rates on different substrates (e.g., Sati and Bisht 2006) and (2) growth rates had to be translated to the coefficient $\gamma$ of our model equations (Table 1). The model was programmed in MATLAB 6.5.

Data of the microcosm experiment were analyzed by univariate and multivariate analyses of variance (AN OVA) followed by planned linear contrasts. These statistical analyses were performed using Statistica version 8.0 (StatSoft 2008).

\section{RESULTS}

Four to eight species sporulated during the experi ment in microcosms, indicating that realistic fungal communities established (Bärlocher 1992) and all but one species succeeded in completing their life cycle (Fig. 2 ). Communities in all treatments were dominated in terms of number of spores produced by Alatospora acuminata, Heliscus lugdunensis, and Tetracladium marchalianum, which together accounted for $8193 \%$ of the total spore production. However, despite similar species composition, there were significant differences among treatments in fungal community structure (MANOVA $F_{32,68}=2.54, P<0.001$ ), caused by shifts in the relative proportion of species when temperature rose from $3^{\circ}$ to $8^{\circ} \mathrm{C}$ (linear contrast $F=6.66, P=0.016$ ). $T$. marchalianum assumed much greater importance at $8^{\circ} \mathrm{C}$, whereas $A$. acuminata and $H$. lugdunensis, which were the most important species at $3^{\circ} \mathrm{C}$, declined in relative abundance (Fig. 2). In contrast to average temperature, diel temperature oscillations did not significantly alter fungal community structure at either $3^{\circ} \mathrm{C}(P=0.93)$ or $8^{\circ} \mathrm{C}$ (linear contrast $F=1.64, P=0.16$; Fig. 2).

Linear contrasts following ANOVA showed that under sterile conditions litter mass loss in microcosms did not differ between $3^{\circ}$ and $8^{\circ} \mathrm{C}$ (Fig. $3 \mathrm{a} ; F_{1,29}=0.078$, $P=0.78$ ), indicating that duration of experiment (i.e., 62 vs. 162 days) had little influence on abiotic mass loss by leaching or abrasion. Leaves decomposed considerably faster in microcosms inoculated with fungi than in sterile controls (Fig. 3a; $P<0.001$ ), with highly significant differences among temperature regimes of microcosms containing fungi $\left(F_{4,25}=8.2, P<0.001\right)$. The average difference in litter mass loss between the $3^{\circ}$ and $8^{\circ} \mathrm{C}$ treatments $(19 \%)$ was also highly significant $\left(F_{1,25}=\right.$ 18.0, $P<0.001$ ), even though our design ensured that total thermal sums (degree days) were virtually the same. Effects of temperature oscillations depended on mean temperature: there was no significant difference in decomposition between constant and oscillating temper atures at a mean temperature of $3^{\circ} \mathrm{C}\left(F_{1,25}=0.13, P=\right.$ $0.72)$, whereas around $8^{\circ} \mathrm{C}$, temperature oscillations of both $5^{\circ}$ and $9^{\circ} \mathrm{C}$ caused $18 \%$ and $31 \%$ faster decompo 

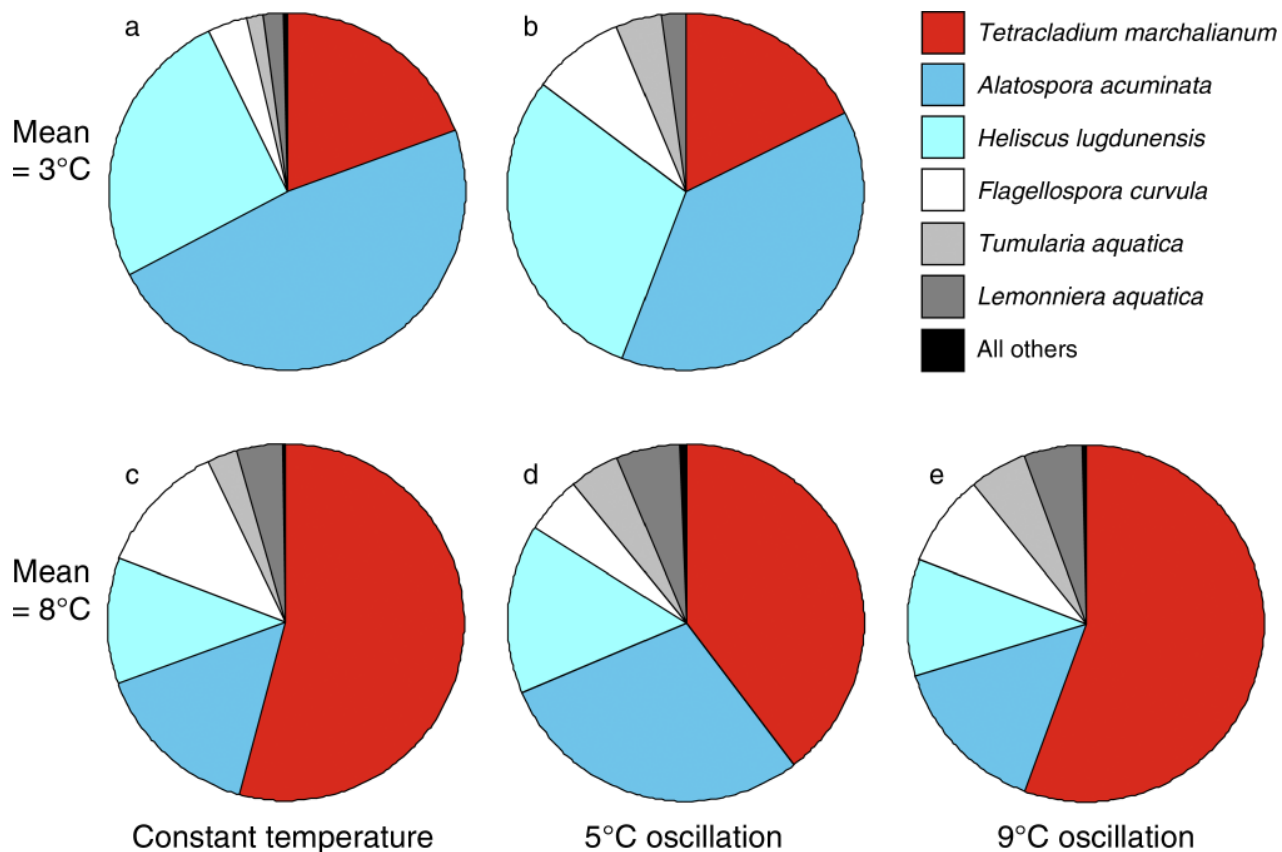

FIG. 2. Fungal community structure on leaves decomposing under regimes of (a, c) constant temperature and (b, d,e) oscillating temperature of $5^{\circ} \mathrm{C}$ or $9^{\circ} \mathrm{C}$ at a mean daily temperature of either $(\mathrm{a}, \mathrm{b}) 3^{\circ} \mathrm{C}$ or $\left(\mathrm{c}\right.$ e) $8^{\circ} \mathrm{C}$. Community structure was inferred from the relative abundance of produced spores.

sition than the constant temperature regime $\left(F_{1,25}=5.1\right.$, $P=0.03$, and $F_{1,25}=14.7, P<0.001$, respectively). The two oscillating temperature regimes did not differ from one another $\left(F_{1,25}=2.50, P=0.13\right)$.

When grown on agar plates, the three dominant fungal species showed the same general growth response to temperature (Fig. 4, Table 2). It was characterized by an initial sigmoid shape (i.e., exponential increase at low temperature and deceleration beyond the inflection point) and eventual decline beyond the maximum (Fig. 4). This type of sigmoid temperature response pattern was well described by an equation originally developed for benthic marine algae (Blanchard et al. 1997). Although general shape of the temperature growth response curves was similar across species, the dominant fungus in the warmer microcosms (i.e., at $8^{\circ} \mathrm{C}$ on average), T. marchalianum, showed a steeper slope around the inflection point than the two other dominant species, A. acuminata and H. lugdunensis (Fig. 4).

The model describing decomposition as a function of fungal community composition, temperature, and time (Table 1, Fig. 5) reproduced the empirically observed lack of a temperature oscillations effect at a mean temperature of $3^{\circ} \mathrm{C}$ (Fig. 3b). Furthermore, it accurately captured the acceleration of decomposition observed when temperatures oscillated by $5^{\circ}$ and $9^{\circ} \mathrm{C}$ around the mean of $8^{\circ} \mathrm{C}$ (Fig. 3b). These findings corroborate our experimental results and suggest that the pronounced sigmoid temperature response patterns of the dominant fungi, particularly of $T$. marchalianum, was instrumental in determining the response of leaf decomposition to temperature oscillations in the $8^{\circ} \mathrm{C}$ warming scenario.

\section{Discussion}

Differences in species responses to warming may critically influence community structure (Walther et al. 2002, Thuiller et al. 2005), and the results reported here suggest this may have consequences not only for species distributions but also for critical ecosystem processes such as litter decomposition. Our results reveal that diel temperature oscillations, in addition to changes in mean temperature, are a critical component of thermal regimes to consider if effects of warming on ecosystem processes are to be accurately predicted. Litter decom position rates were differentially affected by oscillations around $3^{\circ}$ and $8^{\circ} \mathrm{C}$ because all three dominant species in communities had pronounced sigmoid responses to temperature increases. Around $3^{\circ} \mathrm{C}$ the slope of the curve describing fungal activity in response to increasing temperature was nearly flat, so that leaf decomposition rates were not altered by diel oscillations. In contrast, around $8^{\circ} \mathrm{C}$ leaf decomposition was significantly accel erated as a result of the steep slope around the inflection point of temperature growth response curves, particu larly by the species assuming dominance at elevated temperature (Tetracladium marchalianum). This finding suggests that effects caused by diel temperature oscilla tions can be significant even when changes in commu nity structure are relatively minor (i.e., only relative proportions of species in communities change) and 
differences in the species' temperature responses are small. Thus, the reason behind the effect of diel temperature oscillations on decomposition observed under our warming scenario was apparently a combi nation of shifts in community structure and species specific responses to temperature: the dominant species in the community were "selected" by mean temperature and the shape of their temperature response curves determined the extent to which diel temperature oscillations influenced decomposition. Indeed, our model revealed that neither Alatospora acuminata nor Heliscus lugdunensis alone would appreciably accelerate decomposition (Fig. 4d, f), as was experimentally observed (Fig. 3a), whereas simulations involving $T$. marchalianum alone suggest that this species could accelerate decomposition more strongly (Fig. 4b), as also observed in our experiment (Fig. 3a). These data illustrate that dominance of one species or another in a diverse community may alter the response of ecosystem process rates to warming under naturally oscillating temperature regimes (Fig. 5).

Increased mean temperature in our experiment favored a species ( $T$. marchalianum) that tends to be most prevalent in summer in relatively warm temperate streams (e.g., Suberkropp 1984, Gessner et al. 1993). Shifts towards such species exhibiting strong response to temperature increases (and consequent amplification of decomposition rates) might be a common phenomenon in natural communities. This is because responses to warming should be most pronounced in those species that are weak competitors in relatively cold environ ments (e.g., at temperatures between $0^{\circ}$ and $5^{\circ} \mathrm{C}$, which often prevail in late fall and winter in temperate streams) but outgrow their competitors in warmer environments. This rationale is supported by empirical results on temperature growth relationships of various stream fungi. According to data reported in Webster et al. (1976), Suberkropp (1984), Chauvet and Suberkropp (1998), and Rajashekhar and Kaveriappa (2000), most fungal species dominating in temperate streams during fall and winter are less sensitive to temperature increases in the low temperature range than species dominating in warmer conditions, such as in tropical climates or during summer in temperate streams. The same pattern may hold for other microorganisms such as bacteria and microalgae, implying that the effect of temperature oscillations observed in our study could be a common consequence of global warming on decomposition and other ecosystem processes governed by microorganisms.

Because fungal community structure did not notably vary between constant and oscillating temperature regimes at a given mean temperature $\left(3^{\circ}\right.$ or $8^{\circ} \mathrm{C}$ ) (Fig. 3 ), it was possible in our experiment to disentangle the influence of species identity (community structure) from physiological effects. Our results indicate that such physiological effects can be large. In particular, the apparent $\mathrm{Q}_{10}$ of $T$. marchalianum was as high as 17 between $1^{\circ}$ and $11^{\circ} \mathrm{C}$ (Fig. $4 \mathrm{a}$ ), compared to $\mathrm{Q}_{10}$ values
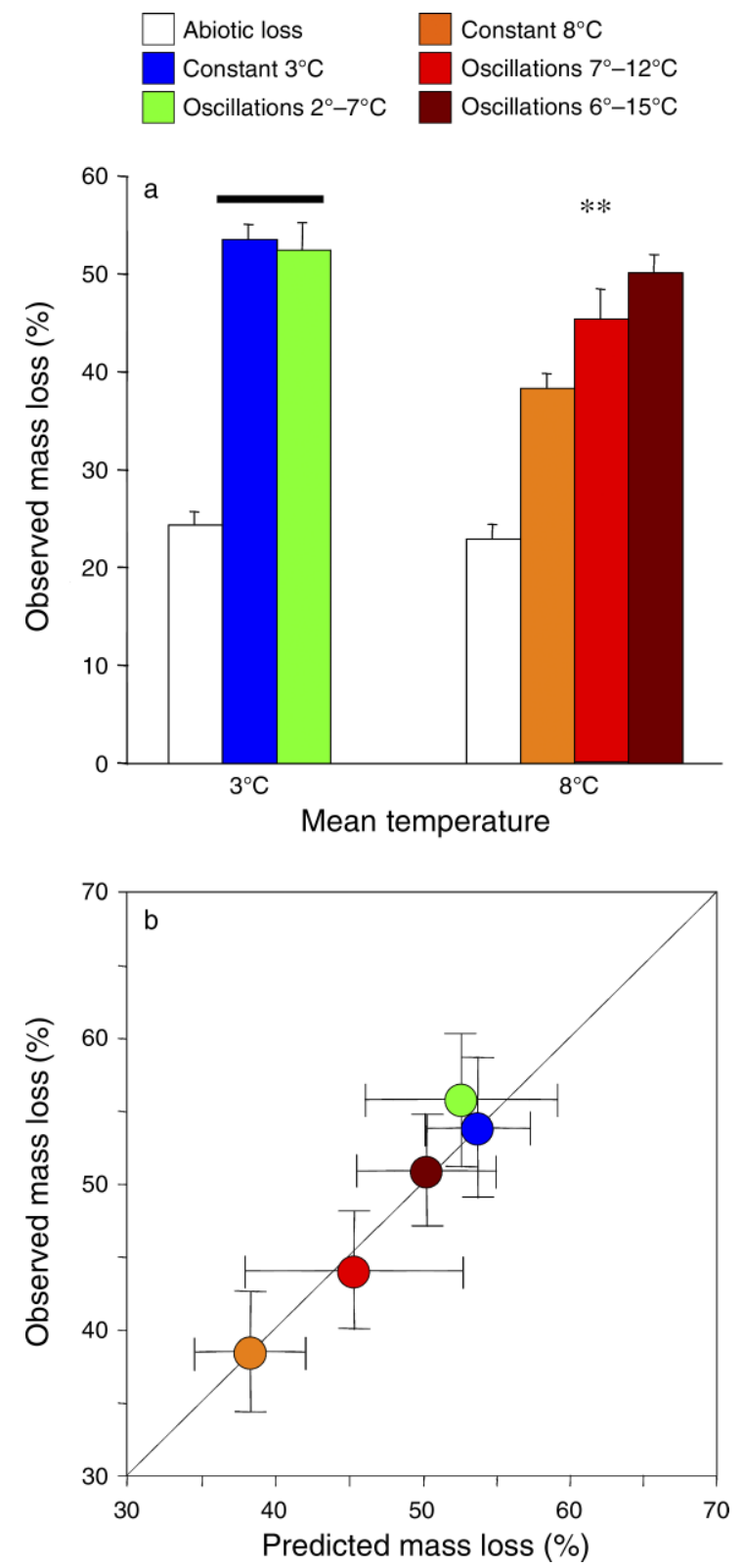

FIG. 3. Mass loss patterns of alder leaves (a) as a function of temperature regimes in stream microcosms and (b) predicted by a simple model for the realized communities at $3^{\circ} \mathrm{C}$ (blue and green symbols) and at $8^{\circ} \mathrm{C}$ (orange, red, and brown symbols). Error bars represent \pm SE. In panel (a), the thick horizontal line at the top indicates a lack of significant difference at $P \quad 0.01$, and the asterisks $(* *)$ denote a significant difference at $P \quad 0.01$ among microcosms containing fungi.

between 2 and 3 commonly used to model responses of organisms to warming (Crohn and Valenzuela Solano 2003, Knorr et al. 2005). Decreases in $Q_{10}$ with decreasing temperature are commonly observed for organic matter decomposition in soils (Kirschbaum 1995, Aerts 2006) and can arise through various mechanisms (Davidson and Janssens 2006). Beyond 

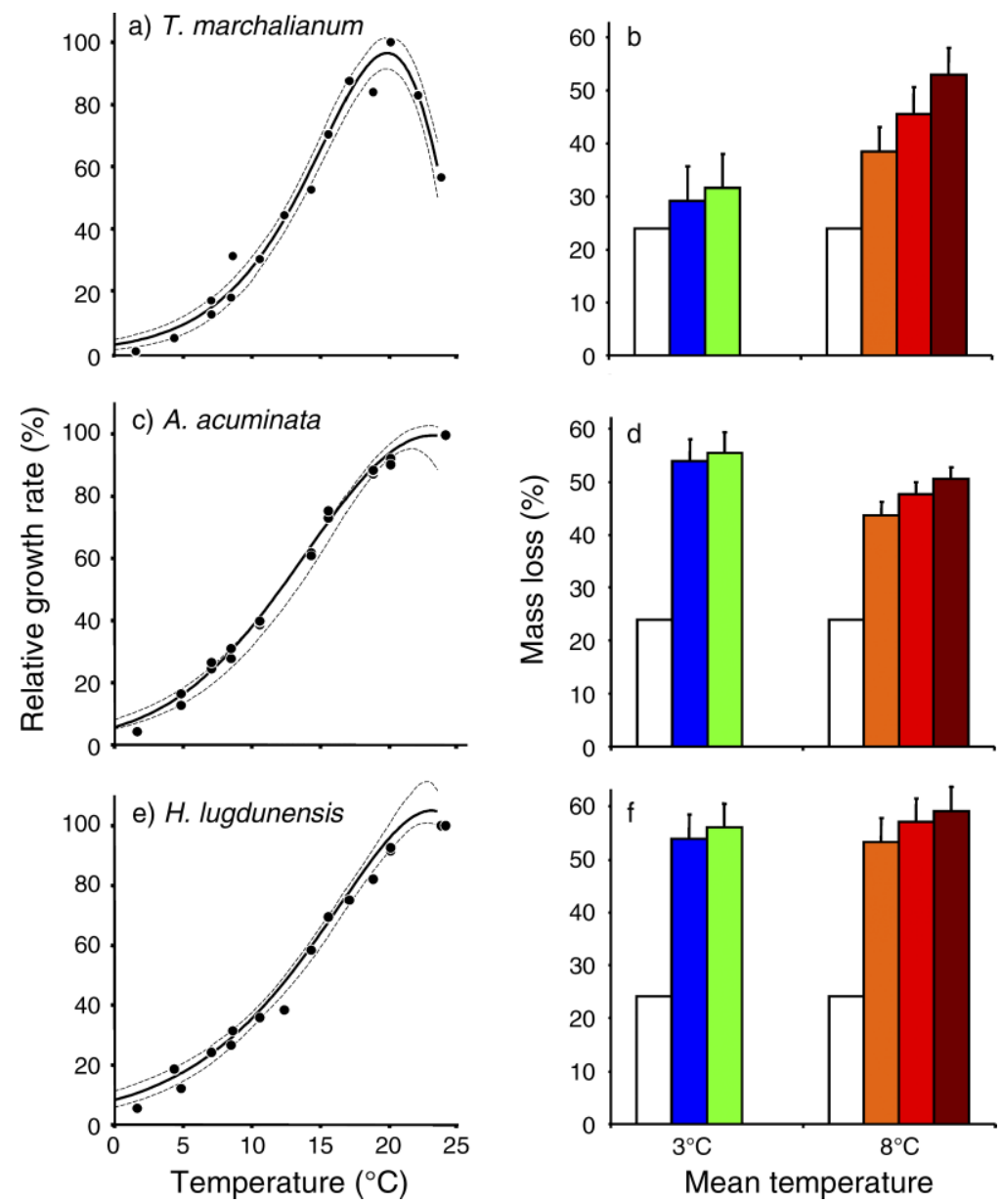

FIG. 4. (Left panels) Temperature growth response curves of the three dominant fungal species (a, Tetracladium marchalianum; c, Alatospora acuminata; e, Heliscus lugdunenesis) during microcosm experiments. Temperature regimes are displayed as in Fig. 3. (Right panels) Mass loss of alder leaves (mean and SE) under different temperature regimes as predicted by a simulation model for the same fungal species. The pronounced sigmoid curve of $T$. marchalianum results in a particularly strong effect on simulated leaf mass loss around $8^{\circ} \mathrm{C}$, with the fungal activity increase between $7^{\circ}$ and $12^{\circ} \mathrm{C}$ being 2.6 times higher than the activity increase between $2^{\circ}$ and $7^{\circ} \mathrm{C}$. The less pronounced curves of $A$. acuminata and $H$. lugdunensis lead to increases in fungal activity of only 1.8 times for both species and correspondingly smaller effects on the simulated leaf mass loss. Solid circles in the left panels represent measured fungal relative growth rates, solid lines indicate regressions using the model by Blanchard et al. (1997), and the broken lines indicate 2.5 and 97.5 percentiles.

the inflection point of temperature response curves, activity gradually decelerates and may thus cause a strong reduction of $\mathrm{Q}_{10}$ with further increases in temperature. For example, according to our empirical data, the $\mathrm{Q}_{10}$ for growth of $T$. marchalianum decreases from 17 to 1.5 , for $A$. acuminata from 4.3 to 2.1 , and for $H$. lugdunensis from 6.3 to 1.8 , when comparing temperature ranges of $1^{\circ} 11^{\circ} \mathrm{C}$ and $10^{\circ} 20^{\circ} \mathrm{C}$. As a consequence, effects on ecosystem processes caused by diel temperature oscillations can be much larger than

TABLE 2. Parameters of temperature growth response curves shown in Fig. 4 (left panels) for the three dominant fungal species (data are mean $\pm \mathrm{SD} ; 200$ bootstraps).

\begin{tabular}{lccccc}
\hline \hline \multicolumn{1}{c}{ Fungal species } & \multicolumn{1}{c}{$\mu_{\mathrm{opt}}(\%) \dagger$} & $T_{\mathrm{opt}}\left({ }^{\circ} \mathrm{C}\right) \ddagger$ & $T_{\max }\left({ }^{\circ} \mathrm{C}\right) \S$ & $\beta() \|$ & $\gamma_{15}\left(\mathrm{~h}{ }^{1} \mathrm{mg}{ }^{1}\right) \boldsymbol{\varphi}$ \\
\hline Tetracladium marchalianum & $96.4 \pm 2.6$ & $20.0 \pm 0.3$ & $28.0 \pm 2.2$ & $3.1 \pm 1.7$ & 3.1104 \\
Alatospora acuminata & $106.7 \pm 3.6$ & $23.0 \pm 0.7$ & $32.2 \pm 6.8$ & $2.5 \pm 2.5$ & 2.2104 \\
Heliscus lugdunensis & $100.2 \pm 1.1$ & $22.5 \pm 0.3$ & $42.4 \pm 3.7$ & $7.1 \pm 1.9$ & 2.6104
\end{tabular}

$\dagger$ Highest relative growth rate.

t Temperature where growth rate is highest.

$\S$ Temperature where growth ceases.

|| Dimensionless scaling factor.

- The coefficient $\gamma$ at $15^{\circ} \mathrm{C}$ predicted by the model described in Table 1 . 

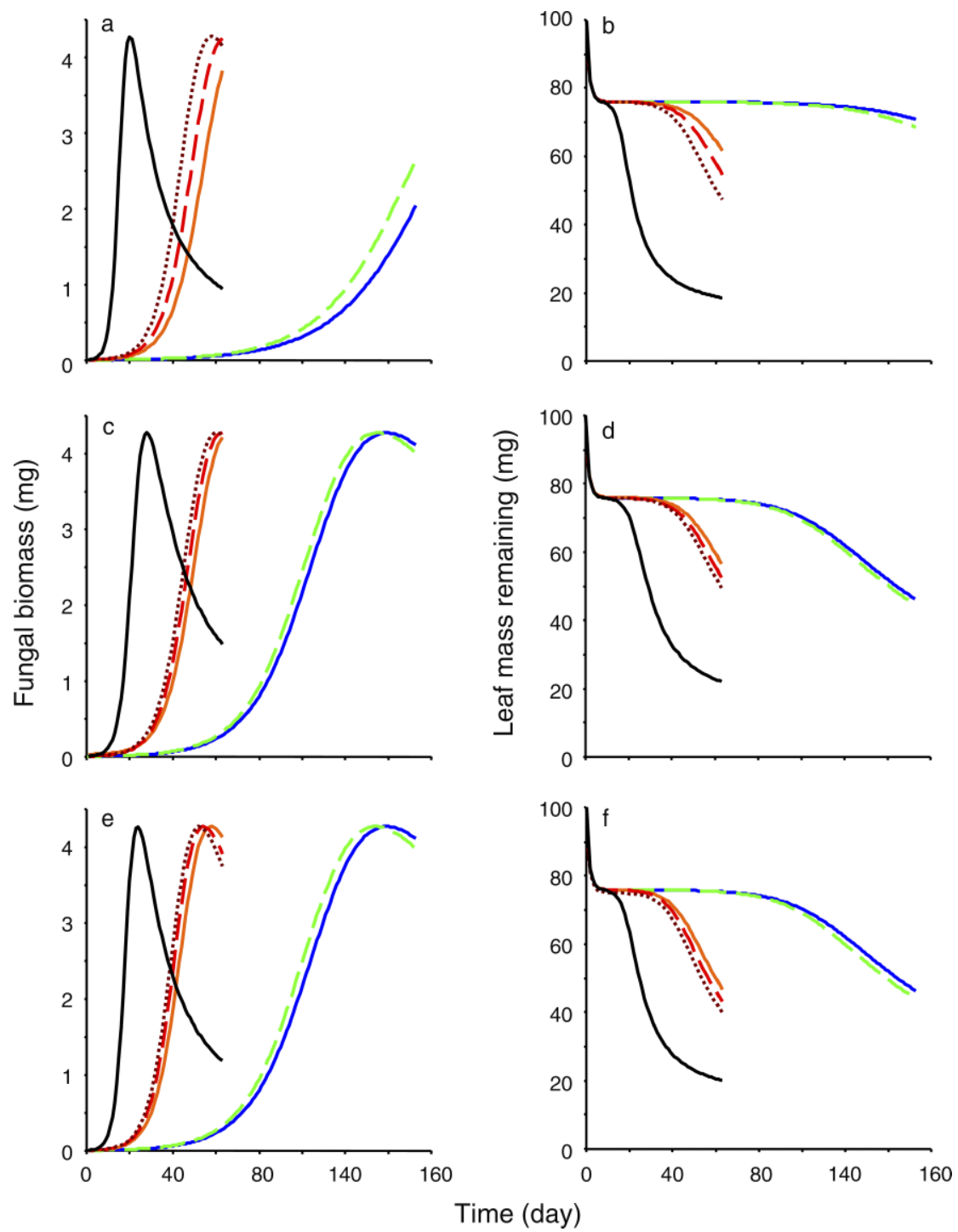

FIG. 5. Output of the simulation model describing changes in fungal biomass and leaf mass remaining for the three dominant fungal decomposers: (a, b) Tetracladium marchalianum, (c, d) Alatospora acuminata, and (e, f) Heliscus lugdunensis. Black solid lines represent fungal biomass and leaf mass loss predicted by the model at a constant temperature of $15^{\circ} \mathrm{C}$. The colored lines (color coding as in Fig 1) represent fungal biomass and leaf mass remaining, predicted at a mean temperature of $8^{\circ}$ and $3^{\circ} \mathrm{C}$. Solid lines represent constant temperature regimes. Dashed and dotted lines represent regimes with diel oscillations of $5^{\circ}$ and $9^{\circ} \mathrm{C}$, respectively.

would be anticipated based on standard linear (degree day) or exponential (Van’t Hoff or Arrhenius with a $Q_{10}$ of 2 4) temperature response models.

That temperature oscillations amplified litter decom position under the warming scenario in our experiment may have implications for forecasting impacts of global change on ecosystem processes in general. Given current consensus that global warming will mainly arise from increases in nighttime temperatures, one would expect decreases in diel temperature amplitudes in the future (IPCC 2007). Analysis of worldwide records of daily maximum and minimum temperatures over the last 50 years indicates indeed a global average trend of decreasing diel temperature amplitudes (Easterling et al.
1997). However, temperature amplitudes were not ubiquitously decreasing, and even increasing over some large areas (Easterling et al. 1997). Thus, decreased diel temperature oscillations could mitigate warming effects on ecosystem processes in most parts of the world, while increased diel oscillations in some other parts could amplify them. These predictions do not take into account alterations in hydrological regimes expected under climate change scenarios. The generally drier conditions predicted for the future (IPCC 2007) may provoke a diminution of stream flow and reduce the capacity of streams to buffer temperature variations on both diel and longer time scales (Caissie 2006). Rates of temperature sensitive process could thus also be affected indirectly. 


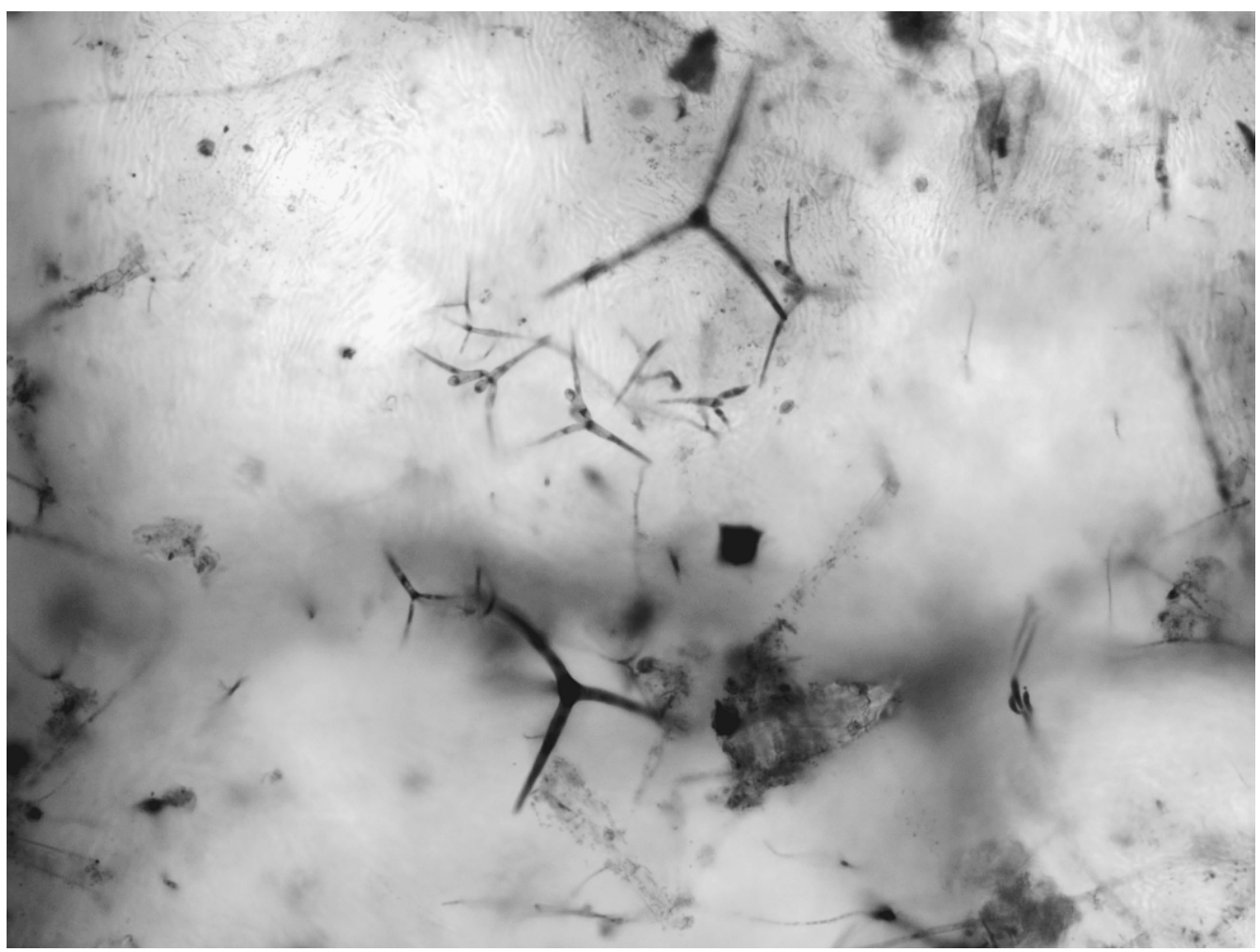

Plate 1. Aquatic hyphomycete spores settled on a leaf. Photo credit: E. Chauvet.

Overall our findings highlight the importance of considering diel temperature oscillations when assessing consequences of global warming on ecosystem function ing. Evidently, such short term fluctuations are most consequential when they affect processes governed by organisms that respond quickly to temperature changes. These include bacteria, fungi, and microalgae, which together drive a large portion of the global biogeochem ical cycles (Field et al. 1998, Falkowski et al. 2000, Davidson and Janssens 2006). The specific temperature growth response patterns of dominant species, and the communities they form, result in responses of ecosystem processes to temperature changes that are distinctly more complex than is generally acknowledged in large scale models. There is a need, therefore, to develop models that take into account diel temperature oscilla tions in concert with community shifts and species and community specific responses to thermal regimes when forecasting effects of global warming on ecosystem processes.

\section{ACKNOWLEDGMENTS}

We thank J. A. Berry, M. A. S. Graça, S. Hattenschwiler, P. Leadley, B. Malmqvist, S. D. Tiegs, S. Vuilleumier, A. Wolf, and the anonymous reviewers, particularly a modeler, for discussion and/or constructive comments on the manuscript. This study was supported by the Swiss State Secretariat for Education and Research (grant number 01.0087) through the RivFunction project funded by the EU Commission (contract number EVK1 CT 2001 00088).

\section{Literature Cited}

Aerts, R. 2006. The freezer defrosting: global warming and litter decomposition rate in cold biomes. Journal of Ecology 94:713 724 .

Barlocher, F. 1992. Community structure. Pages 3876 in F. Barlocher, editor. The ecology of aquatic hyphomycetes. Springer Verlag, New York, New York, USA.

Blanchard, G. F., J. M. Guarini, P. Gros, and P. Richard. 1997. Seasonal effect on the relationship between the photosyn thetic capacity of intertidal microphytobenthos and temper ature. Journal of Phycology 33:723 728.

Buesing, N., and M. O. Gessner. 2006. Benthic bacterial and fungal productivity and carbon turnover in a freshwater marsh. Applied and Environmental Microbiology 72:596 605 .

Caissie, D. 2006. The thermal regimes of rivers: a review. Freshwater Biology 51:1389 1406.

Chauvet, E. 1987. Changes in the chemical composition of alder, poplar and willow leaves during decomposition in a river. Hydrobiologia 148:35 44.

Chauvet, E., and K. Suberkropp. 1998. Temperature and sporulation of aquatic hyphomycetes. Applied and Environ mental Microbiology 64:1522 1525.

Cornelissen, J. H. C., et al. 2007. Global negative vegetation feedback to climate warming responses of leaf litter decomposition rates in cold biomes. Ecology Letters 10: 619627.

Crohn, D. M., and C. Valenzuela Solano. 2003. Modeling temperature effects on decomposition. Journal of Environ mental Engineering 129:1149 1156.

Dang, C. K., E. Chauvet, and M. O. Gessner. 2005. Magnitude and variability of process rates in fungal diversity litter decomposition relationships. Ecology Letters 8:1129 1137. 
Davidson, E. A., and I. A. Janssens. 2006. Temperature sensitivity of soil carbon decomposition and feedbacks to climate change. Nature 440:165 173.

Davidson, E. A., I. A. Janssens, and Y. Q. Luo. 2006. On the variability of respiration in terrestrial ecosystems: moving beyond $\mathrm{Q}_{10}$. Global Change Biology 12:154 164.

Easterling, D. R., B. Horton, P. D. Jones, T. C. Peterson, T. R. Karl, D. E. Parker, M. J. Salinger, V. Razuvayev, N. Plummer, P. Jamason, and C. K. Folland. 1997. Maximum and minimum temperature trends for the globe. Science 277 : 364367.

Falkowski, P., et al. 2000. The global carbon cycle: a test of our knowledge of Earth as a system. Science 290:291 296.

Field, C. B., M. J. Behrenfeld, J. T. Randerson, and P. Falkowski. 1998. Primary production of the biosphere: integrating terrestrial and oceanic components. Science 281: 237240.

Fierer, N., J. M. Craine, K. McLauchlan, and J. P. Schimel. 2005. Litter quality and the temperature sensitivity of decomposition. Ecology 86:320 326.

Gessner, M. O., F. Barlocher, and E. Chauvet. 2003. Qualitative and quantitative analyses of aquatic hyphomy cetes in streams. Pages 127157 in C. K. M. Tsui and K. D. Hyde, editors. Freshwater mycology. Fungal Diversity Press, Hong Kong.

Gessner, M. O., and E. Chauvet. 1994. Importance of stream microfungi in controlling breakdown rates of leaf litter. Ecology 75:1807 1817.

Gessner, M. O., C. T. Robinson, and J. V. Ward. 1998. Leaf breakdown in streams of an alpine glacial floodplain: dynamics of fungi and nutrients. Journal of the North American Benthological Society 17:403 419.

Gessner, M. O., and J. Schwoerbel. 1989. Leaching kinetics of fresh leaf litter with implications for the current concept of leaf processing in streams. Archiv fur Hydrobiologie 115:81 90.

Gessner, M. O., M. Thomas, A. M. Jean Louis, and E. Chauvet. 1993. Stable successional patterns of aquatic hyphomycetes on leaves decaying in a summer cool stream. Mycological Research 97:163 172.

Hieber, M., and M. O. Gessner. 2002. Contribution of stream detrivores, fungi, and bacteria to leaf breakdown based on biomass estimates. Ecology 83:1026 1038 .

Hobbie, S. E. 1996. Temperature and plant species control over litter decomposition in Alaskan tundra. Ecological Mono graphs 66:503 522 .

Hyvonen, R., G. I. Ågren, and P. Dalias. 2005. Analysing temperature response of decomposition of organic matter. Global Change Biology 11:770 778.

IPCC [International Panel on Climate Change]. 2007. Climate change 2007: the physical science basis. Contribution of working group I to the fourth assessment report of the intergovernmental panel on climate change. S. Solomon, D. Qin, M. Manning, Z. Chen, M. Marquis, K. B. Averyt, M. Tignor, and H. L. Miller, editors. Cambridge University Press, Cambridge, UK.

Irons, J. G., M. W. Oswood, R. J. Stout, and C. M. Pringle. 1994. Latitudinal patterns in leaf litter breakdown: Is temperature really important? Freshwater Biology 32:401 411.

Kirschbaum, M. U. F. 1995. The temperature dependence of soil organic matter decomposition and the effect of global warming on soil organic carbon storage. Soil Biology and Biochemistry 27:753 760 .

Knorr, W., I. C. Prentice, J. I. House, and E. A. Holland. 2005. Long term sensitivity of soil carbon turnover to warming. Nature 433:298 301.

Kuehn, K. A., D. Steiner, and M. O. Gessner. 2004. Diel mineralization patterns of standing dead plant litter: impli cations for $\mathrm{CO}_{2}$ flux from wetlands. Ecology 85:2504 2518 .
MathWorks. 2002. MATLAB, version 6.5, release 13. Math Works, Natick, Massachusetts, USA.

Moorhead, D. L., and R. L. Sinsabaugh. 2006. A theoretical model of litter decay and microbial interaction. Ecological Monographs 76:151 174.

Parmesan, C. 2006. Ecological and evolutionary responses to recent climate change. Annual Review of Ecology, Evolution and Systematics 37:637 639.

Pattee, E. 1975. Température stable et température fluctuante. I. Etude comparative de leurs effets sur le développement de certaines Planaires. Internationale Vereinigung fur Theoretische und Angewandte Limnologie, Verhandlungen 19:2795 2802.

Pietikainen, J., M. Pettersson, and E. Bååth. 2005. Comparison of temperature effects on soil respiration and bacterial and fungal growth rates. FEMS Microbiology Ecology 52:49 58 .

Pradhan, S. 1945. Insect population studies. II. Rate of insect development under variable temperature in the field. Proceedings of the National Institute of India 11:74 80 .

Rajashekhar, M., and K. M. Kaveriappa. 2000. Effects of temperature and light on growth and sporulation of aquatic hyphomycetes. Hydrobiologia 441:149 153.

Robeson, S. M. 2002. Relationships between mean and standard deviation of air temperature: implications for global warming. Climate Research 22:205 213.

Sati, S. C., and S. Bisht. 2006. Utilization of various carbon sources for the growth of waterborne conidial fungi. Mycologia 98:678 681.

Schimel, J. P., and M. N. Weintraub. 2003. The implications of exoenzyme activity on microbial carbon and nitrogen limitation in soil: a theoretical model. Soil Biology and Biochemistry 35:549 563 .

StatSoft. 2008. Statistica, version 8. Statsoft, Tulsa, Oklahoma, USA.

Suberkropp, K. 1984. Effect of temperature on seasonal occurrence of aquatic hyphomycetes. Transactions of the British Mycological Society 82:53 62.

Suberkropp, K. 1991. Relationships between growth and sporulation of aquatic hyphomycetes on decomposing leaf litter. Mycological Research 95:843 850.

Sweeney, B. W. 1984. Factors influencing life history patterns of aquatic insects. Pages 56100 in V. H. Resh and D. Rosenberg, editors. Ecology of aquatic insects. Praeger Scientific Publishers, New York, New York, USA.

Thuiller, W., S. Lavorel, M. B. Araujo, M. T. Sykes, and I. C. Prentice. 2005. Climate change threats to plant diversity in Europe. Proceedings of the National Academy of Sciences (USA) 102:8245 8250 .

van der Heide, T., R. M. M. E. Roijackers, E. T. H. M. Peeters, and E. H. van Nes. 2006. Experiments with duckweed moth systems suggest that global warming may reduce rather than promote herbivory. Freshwater Biology 51:110 116.

Vannote, R. L., and B. W. Sweeney. 1980. Geographic analysis of thermal equilibria: a conceptual model for evaluating the effect of natural and modified thermal regimes on aquatic insect communities. American Naturalist 115:667 695.

Walther, G. R., E. Post, P. Convey, A. Menzel, C. Parmesan, T. J. C. Beebee, J. M. Fromentin, O. Hoegh Guldberg, and F. Bairlein. 2002. Ecological responses to recent climate change. Nature 413:389 395.

Webster, J., S. T. Moran, and R. A. Davey. 1976. Growth and sporulation of Tricladium chaetocladium and Lunulospora curvula in relation to temperature. Transactions of the British Mycological Society 67:491 495.

Weston, N. B., and S. B. Joye. 2005. Temperature driven decoupling of key phases of organic matter degradation in marine sediments. Proceedings of the National Academy of Sciences (USA) 102:17036 17040. 